\title{
RUPTURE OF THE AXILLARY ARTERY COMPLICATING DISLOCATION OF THE SHOULDER
}

\author{
Report of a Case
}

\author{
J. F. Curr, Ashington, England
}

From the Department of Surgery, Wansbeck Group of Hospitals, Ashington, Northumberland

An obese man, aged seventy-four, fell on the outstretched hand in February 1956. Clinical and radiological examination an hour later showed subcoracoid dislocation of the right shoulder. Since the injury he had noticed that the right hand was white and cold and that there was no movement in the wrist or fingers. There was no palpable pulsation in the brachial, radial or ulnar arteries. An obvious haematoma was present in the axilla. There was a history of a severe myocardial infarction two years previously.

Under general anaesthesia, two hours after the injury, the dislocation was reduced easily. On recovery from the anaesthetic he felt considerable relief from the shoulder pain but there was no improvement in the circulation of the hand. The haematoma in the axilla continued to enlarge, spreading downwards on the thoracic wall as far as the fifth rib. The general condition deteriorated steadily, due to increasing blood loss. As the limb remained white and cold, it was obvious that there was a serious injury of the axillary artery.

Operation-Four and a half hours after the accident wide exposure was obtained by separation of the deltoid and the pectoralis major and by division of the tendon of the latter. On evacuation of the haematoma there was a sudden, severe gush of blood which was easily controlled by digital pressure over the proximal part of the axillary artery.

It was now seen that the third part of the axillary artery had been severed completely and that the two ends were separated widely, there being a little bleeding from the distal end. The entire artery was rigid and inelastic from advanced arteriosclerosis: it appeared almost to have fractured as though it were a bone. The hard and fragile condition of the vessel made impossible any attempt at direct suture or the insertion of a vein graft or a prosthesis. As the patient's general condition was by no means satisfactory, it was felt that the operation should be concluded without delay. The two ends were ligated and there was no further blood loss. Large branches came off the artery proximal and distal to the sites of ligation, and it seemed that the collateral circulation might prove to be adequate. As a final step, the stellate ganglion was injected with xylocaine.

Progress-On the following day the patient was well and free from pain in the shoulder or hand. The whole limb was warm and of a good colour, and he was able to carry out simple movements of the wrist and fingers. Wound healing was uninterrupted. Subsequently the circulation in the hand remained satisfactory except for a moderate degree of oedema, but no pulse could be felt in the brachial, radial or ulnar arteries. Paralysis of the circumflex nerve and of the ulnar nerve became apparent, and he attended regularly for physiotherapy for six weeks. While at home he suffered another myocardial infarction, preventing further attendance, and he was temporarily lost to follow-up.

Late result-The patient was next seen thirteen years later when he walked into the out-patient clinic. Now aged eighty-eight, he requested operation for a huge inguinal hernia. He had been living alone for six years, leading an active life and enjoying light joinery as a hobby. He denied any disability in the limb. Shoulder movements were nearly perfect. There were no circulatory changes in the hand but the pulses were still absent. Wrist and finger movements were excellent and the grip strong. The operation for repair of the inguinal hernia was carried out safely and he made an excellent recovery. 
Comment-At the time of admission the signs of ischaemia were already pronounced but one could not assess the true degree of vascular injury before reduction of the dislocation. After reduction it became obvious that the vascular injury was severe. Watson-Jones (1955) mentioned how mere pressure on the vessel might be sufficient to cause the hand to be cold and blue, improvement only taking place after reduction.

\section{DISCUSSION}

Types of injury to the axillary artery-Rupture of the axillary artery complicating dislocation of the shoulder is generally thought to be rare. It is interesting that it appeared to be more common in the "horse and buggy" days, when a severe injury might be sustained while coping with a horse out of control, a point mentioned by Archambault, Archambault and Mizeres (1959) and supported by Guibé (1911). There is little reference to the complication in recent publications, and Rowe (1956), in a review of 500 shoulder dislocations, did not mention arterial injury.

It is not proposed to discuss the better known type of injury to the artery when too much force is applied during reduction, especially on an old-standing dislocation. Excluded also are those cases with an associated fracture, those with a direct external injury to the artery and those with an established aneurysm.

When the correct diagnosis has not been made initially, rupture of the artery may present later as a pulsating haematoma or an aneurysm. Another lesion is a complete rupture of the intima without any obvious external damage to the artery but causing total obstruction. Such a case, coming to operation many days later, may present as a localised segment of thrombosis. Of interest, also, are similar lesions of the artery from forcible hyperabduction injury without any sign of a dislocation or fracture.

The paper by Guibé (1911) is of historical importance in view of the large number of cases reported, although not all are relevant to the present discussion. There were thirty-one cases in which the vascular lesion was noticed within three weeks of a dislocation or its reduction; of these, eight were cases of total circular rupture with separation of the ends, and six were cases of incomplete rupture.

End-to-end anastomosis--Rob and Standeven (1956) gave an account of complete rupture of the artery due to dislocation of the shoulder in an elderly patient, end-to-end anastomosis being performed with success. Henson (1956) described a similar case in a man aged seventytwo admitted to hospital four hours after injury, with an excellent result from end-to-end anastomosis. Stener (1957) reported a man aged eighty-seven, admitted to hospital half an hour after injury. There was severe arteriosclerosis and the artery was found completely severed distal to the origin of the subscapular artery; end-to-end anastomosis was performed with excellent result, and eight months later there was a strong radial pulse. Stener also reviewed some earlier cases reported in the German literature. He agreed with Henson that advanced age was an indication in favour of suture rather than against it.

McKenzie and Sinclair (1958) reported two cases. A woman aged seventy-two was submitted to operation seven hours after injury, there being a laceration of the axillary and subscapular arteries; the thrombosed end of the axillary artery was resected and end-to-end anastomosis was performed with excellent result. A man aged sixty-seven was admitted to hospital thirty-six hours after injury, the delay being due to inebriation. At operation ten hours later there was a segment of thrombosed pulseless artery at the site where the subscapular artery had been partly avulsed; resection of the affected segment and end-to-end anastomosis were performed, but gangrene necessitated amputation. The authors stressed the vulnerability of the subscapular and posterior circumflex arteries.

Cranley and Krause (1958) operated on a man aged seventy-three ten hours after injury, resection and end-to-end anastomosis being employed successfully despite marked arteriosclerosis. They also quoted the case of a woman aged fifty-four who had been given treatment 
with heparin for one day, the same technique proving satisfactory. In the case of a woman aged forty-seven, reported by Archambault et al. (1959), there was a rent in the axillary artery where the origin of the thoraco-acromial artery was severed; this was treated successfully by simple suture six hours after the injury.

Ligation of axillary artery-Calvet, Leroy and Lacroix (1941) reported the case of a man aged fifty-nine in whom there was a rupture of the intima, without any external bleeding but with complete obstruction; the affected segment was excised and the ends were ligated, with useful recovery of function. Chauvenet and Daraignez (1942) described two cases. The second case, a woman aged seventy-four, was seen by them four weeks after reduction of a shoulder dislocation; at operation a tear of the atheromatous artery necessitated ligation of both ends. There remained a permanent severe functional disturbance of the hand. Their first case, a man aged sixty-seven, is beyond the scope of this discussion, there being a fracture-dislocation, but it does illustrate the problem of late diagnosis, as operative treatment was not carried out until seventeen days after the injury, with a poor result, disarticulation being required thereafter.

Kirker (1952) described the case of a young man whose dislocation had been reduced at once but who did not see him until three weeks later. At operation, after further observation for ten days, old blood clot was evacuated and there was a tear of the axillary artery necessitating ligation of the subclavian artery. An adequate circulation was restored but an accompanying brachial plexus lesion caused a permanent disability. Johnston and Lowry (1962) discussed the case of a woman aged fifty, operated upon sixteen hours after injury, when complete rupture of the artery was found, with the ends full of thrombus; both ends were ligated and there was full recovery of function below the elbow. Spek (1964), at an early operation on a man aged fifty-five, found a transverse rupture of the axillary artery immediately proximal to the subscapular and posterior circumflex arteries. The lumen of the distal end was closed by sutures to avoid obstructing the branches, and the proximal end was ligated. Ultimate recovery of function was almost perfect.

Early fatality-Watson-Jones (1955) gave an account of a patient who had sustained many recurrent dislocations, easily reduced by himself, until, finally, when an old man with atheromatous vessels, rupture of the artery occurred with a fatal result. Reinisch (1965) described the case of a man aged fifty-three in whom, after a dislocation, there was a fatal haemorrhage from rupture of the axillary artery and vein; hardening and fragility of the vessels were noted and there was a history of previous dislocations.

Miscellaneous lesions following dislocation-Morris (1952) mentioned an unusual example of rupture of the brachial artery but no details were provided. Aupecle, Briet and Butin (1964) operated upon a patient fifty-two days after dislocation, a calcified haematoma being found; a saphenous vein graft was used after resection of a segment of the artery, with a good result except for a residual nerve palsy. Fontaine, Kieny, Pietri and Marotti (1966), while not reporting any case of complete rupture of the artery, gave an account of late cases of thrombosis, pulsatile haematoma and aneurysm, all as complications of dislocation. Domenella and Ciñi (1963) described the progress of two patients whose dislocations were reduced without delay. The first case, in a man aged seventy-three, a sufferer from arteriosclerosis and asthma, demonstrated severe ischaemia without any spreading haematoma in the axilla; operative treatment was not carried out and after three months there remained a serious degree of disability. In the second case, in a man aged forty-two, at early operation there was extensive extravasation of blood due to tearing of the axillary veins; the artery was thrombosed and collapsed, without any bleeding. Arteriectomy and the insertion of a dacron prosthesis were performed but amputation was required on the twentieth day on account of gangrene and severe sepsis.

Injury of artery without obvious dislocation-Totten, Williamson and Armstrong (1962) treated a woman of eighty, four hours after a forcible extension injury by end-to-end anastomosis of a completely ruptured artery; they presumed that the mechanism was a dislocation which

VOL. 52 B, NO. 2, MAY 1970 
had undergone spontaneous reduction. Gibson (1962) suggested the possibility of temporary subluxation in two patients with complete rupture of the artery in whom no dislocation or fracture was noted. In a man aged sixty-two a vein graft was inserted seven hours after injury but death occurred from bronchopneumonia. In a woman aged seventy-one end-to-end anastomosis was employed three hours after injury but there was residual weakness of the hand. Nevertheless, he strongly recommended repair of the artery in preference to ligation. Honton, Leroy, Maumy and Raulin (1963) reported a similar case. St John, Scudder and Stevens (1945) recorded the unusual case of a youth aged fifteen who sustained a complete rupture of the axillary artery while throwing a forward pass at football; ligation of the artery was performed on the second day but death occurred a day later.

\section{CONCLUSIONS}

A study of previous records has shown that most cases of rupture of the axillary artery complicating shoulder dislocation occur in elderly patients with well marked arteriosclerosis. Tethered by its branches and no longer elastic, the rigid artery tends to tear or fracture instead of stretching like a healthy vessel. Alternatively there may be avulsion of a branch.

In the case here reported, the diagnosis of a serious arterial injury was obvious and success in restoring the circulation may be attributed to the prompt treatment rather than to the actual operative technique. Even with unfavourable features of old age and arteriosclerosis, the collateral circulation is evidently quite adequate, provided it is not obstructed itself for too long by a huge haematoma.

When previous records are reviewed it is surprising that there was sometimes a delay of days or even weeks before the arterial injury was suspected. The most important factor in success is undoubtedly early operation, and almost all cases with permanent disability or requiring amputation were associated with delay. The actual technique of operation is probably not so important, and success or failure can occur with any method. In favourable conditions end-to-end anastomosis is no doubt the ideal method, but arteriectomy and the insertion of a vein graft or a prosthesis may be desirable. The simple operation of ligation of the end of the artery can be as effective as any, being particularly valuable when the ends of the artery are unsuitable for holding sutures and when speed is essential.

The injury is serious and can be associated with great risks to life and limb. In the past there was a high mortality, as shown by Calvet et al. (1941). With early diagnosis and modern methods of treatment there is no reason for a high mortality rate, nor for so much severe permanent disability.

\section{SUMMARY}

1. Complete rupture of the axillary artery caused by dislocation of the shoulder in a man aged seventy-four is reported. There was severe arteriosclerosis and the simple operation of ligation of the artery was performed with success. There was excellent function of the shoulder and hand on review thirteen years later.

2. Previously recorded cases are reviewed.

I wish to thank Mr Alan White, at that time resident surgical officer, for his very prompt diagnosis, and Dr J. B. Gibson, consultant anaesthetist, for his attention to a poor-risk patient on three occasions. I am greatly indebted to Miss M. King. Medlars liaison officer, University of Newcastle-upon-Tyne, and to the librarians of the Royal Society of Medicine, the British Medical Association and the Royal College of Surgeons of Edinburgh for their invaluable help in providing foreign references.

\section{REFERENCES}

Archambault, R., Archambault, H. A., and Mizeres, N. J. (1959): Rupture of Thoraco-acromial Artery in Anterior Dislocation of the Shoulder. American Journal of Surgery, 97, 782.

AupeCle, P., Briet, S., and Butin, J. (1964): Luxation antéro-interne de l'épaule droite. Lyon Chirurgical, 60, 101 . 
Calvet, J., Leroy and Lacroix (1941): Luxations de l'épaule et lésions vasculaires. Journal de Chirurgie, 58, 337.

Chauvenet, A., and Daraignez, J. (1942): Sur deux cas de rupture traumatique de l'artère axillaire. Mémoires de l'Académie de Chirurgie, 68, 132.

Cranley, J. J., and Krause, R. J. (1958): Injury to the Axillary Artery following Anterior Dislocation of the Shoulder. American Journal of Surgery, 95, 524.

Domenella, G., and CiÑi, S. (1963): Lesioni Traumatiche Vasali Quali Complicanze della Lussazione Anteriore di Spalla. Chirurgia degli Organi di Movimento, 52, 190.

Fontaine, R., KienY, R., Pietri, J., and Marotti, F. (1966): Les complications artérielles au cours des luxations de l'épaule et de leurs suites. Annales de Chirurgie, 20, 1048.

GiBson, J. M. C. (1962): Rupture of the Axillary Artery. Journal of Bone and Joint Surgery, 44-B, 114.

GuiBé (1911): Des lésions des vaisseaux de l'aisselle qui compliquent les luxation de l'épaule. Revue de Chirurgie, 44, 580.

Henson, G. F. (1956): Vascular Complications of Shoulder Injuries. Journal of Bone and Joint Surgery, 38-B, 528.

Honton, LeRoy, MAUmy and RAulin (1963): Rupture artérielle axillaire après un traumatisme fermé de l'épaule. Bordeaux Chirurgical, 2, 76.

Johnston, G. W., and Lowry, J. H. (1962): Rupture of the Axillary Artery Complicating Anterior Dislocation of the Shoulder. Journal of Bone and Joint Surgery, 44-B, 116.

KIRKeR, J. R. (1952): Dislocation of the Shoulder Complicated by Rupture of the Axillary Vessels. Journal of Bone and Joint Surgery, 34-B, 72.

McKenzie, A. D., and Sinclair, A. M. (1958): Axillary Artery Occlusion Complicating Shoulder Dislocation. Annals of Surgery, 148, 139.

Morris, S. (1952): Rupture of the Brachial Artery Complicating Dislocation of the Shoulder. Journal of Bone and Joint Surgery, 34-B, 160.

ReINISCH, H. (1965): Uber eine seltene Komplikation einer traumatischen Schultergelenksluxation mit tödlichem Ausgang. Archiv für Orthopädische und Unfall-Chirurgie, 57, 194.

Rob, C. G., and Standeven, A. (1956): Closed Traumatic Lesions of the Axillary and Brachial Arteries. Lancet, i, 597.

Rowe, C. R. (1956): Prognosis in Dislocations of the Shoulder. Journal of Bone and Joint Surgery, 38-A, 957.

St John, F. B., Scudder, J., and Stevens, D. L. (1945): Spontaneous Rupture of Axillary Artery. Annals of Surgery, 121, 882.

SPEK, A. Van der (1964): Rupture of the Axillary Artery as a Complication of Dislocation of the Shoulder. Archivum Chirurgicum Neerlandicum, 16, 113.

Stener, B. (1957): Dislocation of the Shoulder Complicated by Complete Rupture of the Axillary Artery. Journal of Bone and Joint Surgery, 39-B, 714.

Totten, H. P., Williamson, W. T., and Armstrong, J. B. (1962): Effort Rupture of the Axillary Artery in a Closed Injury. Journal of the International College of Surgeons, 37, 422.

Watson-Jones, Sir R. (1955): Fractures and Joint Injuries. Fourth edition, Vol. II, p. 479. Edinburgh and London: E. \& S. Livingstone Ltd. 